\title{
PERFILES CONSTITUCIONALES DEL CONSEJO EN EL TRATADO DE ROMA DE 29 DE OCTUBRE DE 2004
}

\author{
LUIS JIMENA QUESADA
}




\section{SUMARIO}

1. Consideraciones INTRODUCTORIAS: El CONSEJO, ENTRE LA CAPACIDAD DE DECIDIR Y LA VOLUNTAD DE DECIDIR. 2. CONFIGURACIÓN Y DECURSO HISTÓRICOS DEL Consejo en la Unión Europea. 2.1. Del Consejo de Ministros... al Consejo de Ministros. 2.1.1. La confirmación del peso prevalente de los intereses estatales. 2.1.2. Su caracterización como máxima instancia política decisoria a escala europea. 2.2. Configuración y decurso históricos del Consejo Europeo. 2.2.1. De las informales "cimas europeas" a la institucionalización del Consejo Europeo. 2.2.2. Su diseño como máxima instancia política constituyente de la Unión Europea. 3. LA CONSTITUCIONALIZACIÓN DE EUROPA A TRAVÉS DE LA CONSTITUCIONALIZACIÓN DEL CONSEJO. 3.1. Un nuevo reparto de poder en el seno del Consejo de Ministros. 3.2. La constitucionalización de la figura del Ministro europeo de asuntos exteriores como ministro "bicéfalo». 3.3. El nuevo cariz institucional del Consejo Europeo. 3.4. El Presidente del Consejo Europeo como Presidente de la Unión Europea. 4. REFLEXIONES FINALES: EL CONSEJO, ¿UN PODER CONSTITUYENTE O UN PODER CONSTITUIDO PARA GENERAR EL DEMOS EUROPEO? 


\title{
PERFILES CONSTITUCIONALES DEL CONSEJO EN EL TRATADO DE ROMA DE 29 DE OCTUBRE DE 2004*
}

\author{
POR \\ LUIS JIMENA QUESADA \\ Profesor Titular de Derecho Constitucional \\ Universidad de Valencia
}

\section{CONSIDERACIONES INTRODUCTORIAS: EL CONSEJO, ENTRE LA CAPACIDAD DE DECIDIR Y LA VOLUNTAD DE DECIDIR}

De entrada, y en este momento de la construcción europea, incluso las posturas más optimistas en torno al proceso de "constitucionalización" de Europa no pueden ocultar que la institución más decisiva y de mayor poder de la Unión Europea continúa siendo el Consejo, y ello tanto si nos referimos al Consejo de la Unión en sentido estricto como institución comunitaria (el inicial Consejo de Ministros según los Tratados comunitarios y, por cierto, también según el Tratado por el que se establece una Constitución para Europa de 29 de octubre de 2004 -en adelante, Tratado constitucional-), como si aludimos al Consejo Europeo en su formación de Jefes de Estado y de Gobierno (que según el Tratado constitucional adquirirá el rango de institución -infra-).

* El presente trabajo se ha elaborado en el marco del Grupo «Estudio Multidisciplinar sobre Integración Europea" cuyo investigador principal es el doctor Valentín Bou Franch (referencia: grupo S05/025, Generalitat Valenciana). 
En efecto, como es sabido, el Consejo de la Unión o Consejo de Ministros (en lo sucesivo, el Consejo) ostenta la máxima capacidad de decidir acerca de la realización de las políticas y de las competencias que tiene atribuidas la Unión o, en otros términos, constituye el órgano de mayor poder decisorio en lo que atañe a la profundización y dinamización interna de la Unión; por ello, no resulta extraño que en el sitio web oficial de la Unión (www.europa.eu.int) se diga expressis verbis que el Consejo «es el principal centro de decisión política de la Unión». Por su parte, el Consejo Europeo ostenta la más elevada voluntad de decidir sobre la eventual extensión del ámbito de acción de las políticas y competencias ya atribuidas a la Unión, así como a la atribución de nuevas políticas y competencias o, en otras palabras, se erige en la plataforma de mayor potencial decisorio en lo que concierne a la proyección de la Unión.

Lo acabado de reseñar ha sido así desde el origen de las Comunidades Europeas y está previsto que continúe del mismo modo en el Tratado constitucional de 2004. Y ello no se ve disminuido un ápice por la apreciación - por lo demás, acertada- según la cual en la Unión Europea el juego de pesos y contrapesos en el reparto del poder habría conocido una evolución inversa a la sucedida en el seno de los Estados miembros, es decir, que mientras los Parlamentos estatales habrían perdido "centralidad" frente al fortalecimiento de los Ejecutivos" ${ }^{\text {, la }}$ tendencia en la Unión ha consistido en compensar y dotar de mayor protagonismo a un débil Parlamento Europeo aquejado - por ello mismo- del ya clásico déficit democrático ${ }^{2}$.

Así, si con razón se ha destacado que el Parlamento Europeo es el único foro parlamentario transnacional o plurinacional elegido por sufragio universal, semejante consideración de "democracia procedimental» no guarda paralelismo con las funciones reales de aquél frente a los dos ejes básicos del poder ejecutivo europeo (la Comisión y el Consejo); efectivamente, de forma paradójica no nos encontramos ante una asamblea legislativa con capacidad para elaborar y para aprobar leyes europeas, ya que: de un lado, la Comisión Europea ostenta el cuasimonopolio de la iniciativa legislativa (input); y, de otro lado, la decisión sobre el producto final (output) la comparten la Eurocámara y el Consejo. Tal

1 Esta terminología se ha empleado en el Derecho comparado italiano: cfr. ToMÁs MALLÉN, B.: «La reforma de 1997 del Reglamento de la Cámara de los Diputados italiana: hacia la recuperación de la centralidad del Parlamento", Revista de las Cortes Generales, n. ${ }^{\circ}$ 48, 1999.

2 Attina, F.: Introducción al sistema político de la Comunidad Europea, Madrid, Centro de Estudios Constitucionales, 1992. 
extremo lo confirma el artículo l-34 del Tratado constitucional de 2004 (actos legislativos): mientras su apartado 1 dispone que "las leyes y leyes marco europeas serán adoptadas, a propuesta de la Comisión, conjuntamente por el Parlamento Europeo y el Consejo por el procedimiento legislativo ordinario contemplado en el artículo III-396. Si ambas instituciones no llegan a un acuerdo, el acto no se adoptará", su apartado 2 establece que "en los casos específicos previstos por la Constitución, las leyes y leyes marco europeas serán adoptadas por el Parlamento Europeo con la participación del Consejo, o por éste con la participación del Parlamento Europeo, con arreglo a procedimientos legislativos especiales ${ }^{3}$. En síntesis, si la Eurocámara ha transitado desde su original diseño como foro meramente consultivo hacia su consolidación como institución codecisora (básicamente, colegisladora), no por ello ha visto reducido su poder decisorio (si acaso, mitigado) el Consejo, y así lo confirman los artículos I-20 y I-23 del Tratado constitucional de $2004^{4}$.

Con análoga orientación, y por -entre otras - las razones expresadas, si es común destacar que la Comisión Europea configura la institución más original del sistema institucional de la Unión y el mejor reflejo de los postulados funcionalistas, no es menos cierto que resulta ser más que la mera "Administración Pública europea» ${ }^{5}$, pero sin llegar a constituir el verdadero "Gobierno europeo" 6 . En el mejor de los casos, puede sostenerse que el Ejecutivo de la Unión es bicéfalo (el refe-

3 Por lo demás, según el apartado 3 del artículo I-34: «En los casos específicos previstos por la Constitución, las leyes y leyes marco europeas podrán ser adoptadas por iniciativa de un grupo de Estados miembros o del Parlamento Europeo, por recomendación del Banco Central Europeo o a petición del Tribunal de Justicia o del Banco Europeo de Inversiones".

${ }^{4}$ Con redacción idéntica, mientras el artículo I-20.1 dispone que «el Parlamento Europeo ejercerá conjuntamente con el Consejo la función legislativa y la función presupuestaria", el artículo I-23.1 establece que "el Consejo ejercerá conjuntamente con el Parlamento Europeo la función legislativa y la función presupuestaria».

${ }^{5}$ Cfr. Montero Casado de Amenzúa, J., y Calleja Crespo, D.: "La Administración de la Unión Europea", en la obra colectiva Administraciones Públicas y Constitución. Reflexiones sobre el XX Aniversario de la Constitución Española de 1978 (coord. E. Álvarez Conde), Madrid, Instituto Nacional de Administración Pública, 1998, p. 1049.

6 Véase TOMÁs MALLÉN, B.: El derecho fundamental a una buena administración, Madrid, INAP, 2004, pp. 6266: «de entrada, si se efectúa un paralelismo con el sistema institucional de los Estados, el conocido binomio 'Gobierno y Administración' (en el caso español, tal es la rúbrica del Título IV de la Ley de Leyes) tendría su trasunto en la Comisión de la Unión Europea y en su administración", aunque profundizando al respecto, "sólo la organización administrativa de la Comisión (y, en menor sentido, del Consejo), como Administración en sentido clásico (del Ejecutivo), se haría acreedora del calificativo Administración europea». 
rido eje Comisión-Consejo), siendo precisamente más débil la primera rama, que como es sabido tiene su origen en la Alta Autoridad de los Tratados constitutivos, según la previsión de la Declaración Schuman de 1950. Tampoco es ajena al ámbito de la Unión la figura de las autoridades administrativas independientes ${ }^{7}$, con los problemas de constitucionalidad que puede comportar su funcionamiento, también en el contexto del Tratado constitucional ${ }^{8}$.

En estas coordenadas, la tensión que se genera en el proceso de construcción europea entre, por una parte, la gran capacidad de decidir del Consejo y la frecuente predisposición al bloqueo en su seno y, por otra parte, el enorme potencial de voluntad decisoria del Consejo Europeo y la correlativa falta de determinación para ejercerla en ciertos momentos claves, han conducido a que el Consejo y el Consejo Europeo sean percibidos como entes europeos impopulares y, al tiempo, profundamente desconocidos. En cuanto a lo primero, recuérdese cómo, con motivo de la campaña electoral del referéndum español de 20 de febrero de 2005 sobre la Constitución europea, el líder de la oposición Mariano Rajoy rechazó la invitación del presidente del Gobierno

7 Se trata de las agencias comunitarias, configuradas como organismos de Derecho público europeo, distintos de las instituciones comunitarias (Consejo, Parlamento, Comisión, etc.) y que poseen una personalidad jurídica propia. Las agencias comunitarias se crean mediante un acto comunitario de Derecho derivado con el fin de desempeñar una tarea específica de naturaleza técnica, científica o de gestión que se especifica en el correspondiente acto fundacional. Hay actualmente diecisiete organismos que responden a esta definición de agencia comunitaria, si bien las palabras empleadas para designar a estos organismos son varias (Centro, Fundación, Agencia, Oficina, Observatorio) y pueden dar lugar a cierta confusión, sobre todo teniendo en cuenta que otros organismos que utilizan estas mismas denominaciones no son agencias según esta definición. Esas diecisiete agencias son: el Centro Europeo para el Desarrollo de la Formación Profesional; la Fundación Europea para la Mejora de las Condiciones de Vida y de Trabajo; la Agencia Europea de Medio Ambiente; el Observatorio Europeo de la Droga y las Toxicomanías; la Agencia Europea de Medicamentos; la Oficina de Armonización del Mercado Interior (Marcas, Dibujos y Modelos); la Agencia Europea para la Seguridad y la Salud en el Trabajo; la Oficina Comunitaria de Variedades Vegetales; el Centro de traducción de los órganos de la Unión Europea; el Observatorio Europeo del Racismo y la Xenofobia; la Agencia Europea de Reconstrucción; la Autoridad Europea de Seguridad Alimentaria; la Agencia Europea de Seguridad Marítima; la Agencia Europea de Seguridad Aérea; la Agencia Europea de Seguridad de las Redes y de la Información; y el Centro europeo para la prevención y el control de las enfermedades.

8 Cfr., para el caso español, con análisis de algunos elementos comparados, RALLo Lombarte, A.: La constitucionalidad de las administraciones independientes, Tecnos, Madrid, 2002. 
José Luis Rodríguez Zapatero de participar en un "euromitin» con el Presidente de la República Francesa Jacques Chirac y con el entonces Canciller Gerhard Schröder; para justificar dicho rechazo, arguyó Rajoy como pretexto que no le parecía decoroso hacer campaña proeuropeísta al lado de dos de los dirigentes europeos que habrían pretendido restarle poder a España en el Consejo, señaladamente en el texto constitucional europeo. En lo que afecta a lo segundo, es menester advertir que se produce una suerte de confusión en el conocimiento de qué sea exactamente tanto el Consejo como, sobre todo, el Consejo Europeo, en particular al confrontarlo con el Consejo de Europa; y ese desconocimiento aflora incluso en medios de comunicación, con la trascendencia que ello posee si se tiene presente el papel de los mass media como ámbito de educación no formal que contribuye a forjar una cultura jurídica, una identidad europea.

\section{CONFIGURACIÓN Y DECURSO HISTÓRICOS DEL CONSEJO EN LA UNIÓN EUROPEA}

\subsection{Del Consejo de Ministros... al Consejo de Ministros}

2.1.1. La confirmación del peso prevalente de los intereses estatales

Dejando ahora de lado la caracterización del Consejo en el Tratado constitucional de 2004, la verdad es que para confirmar el peso prevalente de los intereses estatales representados por dicha institución comunitaria en la historia de la construcción europea, basta ponderar el alcance de la última gran reforma vigente de los Tratados comunitarios, es decir, el Tratado de Niza de 2001. Como se recordará, fue precisamente el reparto de poder en el seno del Consejo la cuestión que eclipsó el resto de realizaciones europeas y, peor aún, bloqueó uno de los máximos anhelos de la ciudadanía europea, la Carta de los derechos fundamentales de la Unión (o Carta de Niza) ${ }^{9}$.

9 En la viabilidad de esas expectativas más garantistas para los ciudadanos deben colaborar, evidentemente, no sólo los Estados miembros a través de sus gobiernos, sino asimismo los órganos que tengan atribuida entre sus competencias la importantísima de actuar a nivel interno como pieza de cierre del sistema de derechos fundamentales, como sucede con los Tribunales Constitucionales: en esa faceta de colaboración no habría que desvirtuar mecanismos de colaboración como la cuestión prejudicial formulada, también por esos Tribunales Constitucionales nacionales, ante el Tribunal de Justicia comunitario: véase un amplio estudio comparado sobre el particular en la obra de VIDAL PRADO, C.: El impacto del nuevo Derecho europeo en los Tribunales Constitucionales, Madrid, Colex, 2004. 
Ese peso específico del Consejo se ha visto favorecido por los vaivenes evolutivos de la institución defensora del interés comunitario (la Comisión) y de la institución representativa de los pueblos europeos (el Parlamento Europeo). En cuanto a la primera, es conocido que la Comisión Europea ha tenido que pugnar en su "eurodinamismo" en la búsqueda de intereses comunes con las reticencias soberanas o el "euroescepticismo" de algunos Estados miembros en el seno del Consejo. En este ambiente, uno de los períodos más dinámicos del rol jugado por la Comisión en la construcción europea estuvo marcado, a mediados de los años ochenta del siglo pasado, por el equipo presidido por Jacques Delors, que lanzó en el año 1985 el Libro blanco sobre el mercado interior y el Acta Única Europea: dicho documento tuvo el mérito de fijar una fecha límite (1992) que, sin llegar a cumplirse, impulsó de manera decisiva las políticas comunitarias para avanzar en una trayectoria imparable hacia el diseño de la gran Unión Europea en el Consejo Europeo de Maastricht de diciembre de 1991.

Lo bien cierto es que, tras la autoridad que imprimió el francés Jacques Delors a la Comisión Europea (1985-1994), la sucesión al frente de la presidencia de ella por el luxemburgués Jacques Santer (1995-2000) no fue tan afortunada (con una moción de censura presentada por la Eurocámara que, no obstante no haber prosperado, erosionó la credibilidad de la Comisión). Por lo demás, los dos presidentes ulteriores de la Comisión Europea (el ex primer ministro italiano Romano Prodi -2001-2005- y el ex primer ministro portugués José Manuel Barroso -2005-2009_) no han mostrado un carisma comparable al de Jacques Delors. Así las cosas, el actual presidente de la Comisión, señor Barroso, ante el actual bloqueo del proceso de ratificación del Tratado constitucional de 2004 como consecuencia de las consultas populares negativas en Francia y en Holanda, ha alertado acerca de las repercusiones negativas de esa prevalencia desmedida de las intereses estatales sobre el pretendido liderazgo mundial de la Unión Europea en su competencia con las otras dos grandes zonas comerciales del mundo (Estados Unidos y Japón - por no hablar de la irrupción del "gigante chino" $\left.{ }^{10}-\right)$, especialmente en el contexto de la globalización ${ }^{11}$.

10 Véase la sentencia del Tribunal de Primera Instancia de 28 de octubre de 2004 (asunto T-35/01, caso Shanghai Teraoka Electronic Co. Ltd, contra Consejo de la Unión Europea, sobre establecimiento de derechos antidumping definitivos en que entran en juego balanzas electrónicas originarias de China). De todos modos, con independencia del temor a la concurrencia china, el alcance de la deslocalización ya está presente desde la última ampliación, como ha puesto de relieve TORRES DEL MoRAL, A.: "El Estado internacionalmente integrado», en su obra Estado de Derecho $y$ 
En lo que atañe al Parlamento Europeo, desde su posición más modesta, también ha intentado compensar el arraigo de los intereses estatales en algunos ámbitos en los que, no ya tanto el Consejo, sino directamente los países miembros de la Unión, han optado por hacer prevalecer los intereses estatales en perjuicio de una política común progresivamente asentada en el método integracionista. Así ha ocurrido en política de inmigración y asilo: concretamente, la Eurocámara, como institución más afectada por el déficit democrático, en su Informe sobre los derechos humanos en el mundo y la política de la Comunidad correspondiente al período 1991-1992" "lamenta el hecho de que algunos Estados miembros hayan empezado a reducir la protección legal y la seguridad social de las personas que buscan asilo, (...) deplora que estas medidas no contengan garantías relativas a la protección de los derechos fundamentales, en particular para aquéllos que buscan asilo". Y añade a renglón seguido, que "lamenta el carácter intergubernamental [se refería al Convenio de Aplicación de Schengen de 19 de junio de 1990 y al Convenio de Dublín de 15 de junio de 1990] de las medidas iniciales tomadas para armonizar el estatuto de los nacionales de terceros Estados en la Comunidad. (...) desea Ilamar la atención sobre el peligro de que Europa se convierta en una fortaleza si los nacionales no comunitarios son discriminados, en contra de los principios en los que se basa el orden comunitario" ${ }^{13}$.

democracia de partidos, Madrid, Universidad Complutense, 2. ${ }^{\text {a }}$ ed., 2004, p. 128: "otro de los primeros efectos de la ampliación europea de 2004 será la deslocalización de muchas empresas que operan en alguno de los quince Estados anteriores y que ahora preferirán hacerlo en alguno de los diez nuevos, por su más bajo coste de producción, salarios y fiscalidad, muy por debajo de la media de aquéllos. Esto creará posiblemente tensiones y rivalidades, pero tendencialmente se restablecerá un cierto equilibrio a medida que esos países nuevos vayan alcanzando un mayor nivel de renta, aparta del territorio que ofrecen a los países más antiguos para extender su comercio".

11 Léase Barroso, J. M.: "Europe must open up to the globalized world", Herald Tribune, Wednesday, September, 21, 2005, p. 8.

12 Resolución A-30025/92 adoptada el 3 de marzo de 1993, bajo los auspicios del Comité de Libertades Públicas y Asuntos de Interior de la Eurocámara.

${ }^{13}$ En la actualidad, y desde la integración del "acervo de Schengen" operada a través del Tratado de Ámsterdam, se han producido normas estrictamente comunitarias de alcance nada insignificante, como por ejemplo la Directiva 2003/9/CE del Consejo, de 27 de enero de 2003, por la que se aprueban normas mínimas para la acogida de los solicitantes de asilo en los Estados miembros (cuyo plazo de transposición expira, según el artículo 26 de la Directiva, el 6 de febrero de 2005), o la Directiva 2004/83/CE, de 29 de abril de 2004, por la que se establecen normas mínimas relativas a los requisitos para el reconocimiento y el estatuto de nacionales de terceros países o apátridas como refugiados o personas que necesitan otro tipo de pro- 
$Y$, en fin, ciertamente, el peso de los intereses estatales se percibe asimismo en la composición del Consejo. El artículo 203 del Tratado de la Comunidad Europea dispone que el Consejo está integrado por un representante de cada Estado miembro de "rango ministerial», facultado para comprometer al Gobierno de dicho Estado miembro. Ello explica que la denominación anterior fuera la de "Consejo de Ministros". De sobra conocido es que el Consejo de la Unión Europea tiene carácter sectorial, de modo que en cada ocasión se reúnen los ministros del ramo, esto es, los ministros competentes para cada política comunitaria; lo cual conduce a que realmente no haya un solo Consejo, sino tantos Consejos como materias en las que posee competencia la Comunidad (así, hay Consejos de Ministros de Transportes, de Agricultura, de Medio Ambiente, etc.) o, más ampliamente, la Unión Europea en las políticas de cooperación (a este respecto, también se celebran reuniones de Ministros de Justicia, de Interior y de Defensa). Esta naturaleza sectorial del Consejo se impuso desde el momento en que la Comunidad Europea fue asumiendo paulatinamente competencias, lo que lógicamente comportaba mayor complejidad y más especialización por parte del representante gubernamental asistente al Consejo; puesto que, en sus orígenes, en las reuniones del Consejo se daban cita como regla general los Ministros de Asuntos Exteriores de cada país miembro.

Por otra parte, con el cambio de denominación abandonando el calificativo "de Ministros" (que se operó a través del Tratado de Maastricht) y apostillando que el representante gubernamental había de ostentar "rango ministerial", se introdujo una nueva redacción más abierta que cerraba el paso a posibles interpretaciones sesgadas tendentes a vetar la participación de un Estado miembro que no tuviera Ministro competente del ramo a consecuencia de la distribución competencial interna (por ejemplo, en materia de cultura, o de agricultura, etc.). Por añadidura, se daba pie a que pudieran eventualmente intervenir los miembros de gobiernos o consejos ejecutivos (Ilámense ministros, llámense consejeros o denominaciones equiparables) de entidades infraestatales en Estados con estructura territorial federal, como es el caso notorio de los ministros de un Land alemán o de una región belga, o el más controvertido de los consejeros de una Comunidad Autónoma española. Como se verá más tarde, resulta curioso cómo, al tiempo que el Tratado constitucional de 2004 ha pretendido profundizar en el prin-

tección internacional y al contenido de la protección concedida (la expiración del plazo para la adaptación del Derecho nacional se fija en el artículo 38 de la Directiva en el 10 de octubre de 2006). 
cipio de subsidiariedad, ha vuelto a recuperar la denominación «Consejo de Ministros" anterior al Tratado de Maastricht: lo que, dicho sea de paso, desde esta perspectiva nominalista, se dificulta - al menos, simbólicamente- el arraigo de la subjetividad internacional de la Unión ${ }^{14}$.

\subsubsection{Su caracterización como máxima instancia política decisoria a escala europea}

Con lo expuesto hasta ahora, queda claro que el Consejo es la institución comunitaria que, sobre representar el interés de los Estados miembros en los procesos decisorios de la Unión Europea y servir en este sentido de cauce de participación de los Gobiernos, se caracteriza como la máxima instancia política decisoria a escala europea. Aun con todo, reconducir el Consejo a un mero órgano de carácter intergubernamental que representa los intereses estatales comporta una visión bastante reduccionista, siendo más adecuado a la realidad afirmar que constituye el punto de encuentro de los intereses nacionales y los supranacionales, pese al carácter prevalente de los primeros. Sentado lo anterior, la caracterización del Consejo como máximo foro político decisorio de la Unión se ha articulado sobre la base de tres tensos vectores: el primero, la lucha entre los Estados miembros para, de un lado, ir reduciendo paulatinamente los materias susceptibles de ser adoptadas por unanimidad y, de otro lado, conseguir en consecuencia un reparto equilibrado del poder para tomar decisiones por mayoría cualificada; el segundo, el incremento de las materias en las que el Parlamento Europeo participará a título de órgano codecisor con el Consejo; y el tercero, la propia dinámica del reparto del poder ejecutivo entre el Consejo y la Comisión. Veamos estas tres variables por referencia, de momento, a la situación vigente tras el Tratado de Niza.

14 Así lo ha enfatizado FERnÁNDEZ SolA, N.: "La subjetividad internacional de la Unión Europea", Revista de Derecho Comunitario Europeo, n. ${ }^{\circ} 11,2002$, p. 96: sobre esta cuestión, la autora llama la atención sobre una práctica ambigua de la Unión tras el Tratado de Maastricht, "que denota la falta de voluntad política frente a una necesidad jurídica. Así, junta a indicios claramente nominativos tales como el cambio de denominación del Consejo [Decisión del Consejo de 8 de noviembre de 1993, por la que se pasa a denominarse Consejo de la Unión Europea (DOCE n. ${ }^{\circ} \mathrm{L}$ 281/1993)] o de las representaciones estatales acreditadas ante la Organización, nos encontramos con la conclusión de instrumentos jurídicos cuya calificación de 'tratado internacional' es dudosa, como también lo es el título de participación en ellos de la Unión Europea y de sus Estados miembros». 
En lo que concierne a la adopción de acuerdos unánimes en el seno del Consejo, sigue rigiendo la regla de la abstención constructiva, en el sentido de que la abstención o abstenciones de los miembros presentes o representados no impedirán la adopción de las decisiones del Consejo que requieran la unanimidad. Esta regla reviste importancia, puesto que en los primeros años de la construcción europea la regla general era la unanimidad y sin abstención constructiva, de modo que bastaba la oposición, o más sencillamente la abstención, de un Estado miembro, para bloquear la toma de decisiones. Esto fue lo que ocurrió a principios de los sesenta, cuando la disconformidad de Francia con la política agrícola pactada por los demás Estados miembros condujo al Ministro francés de asuntos exteriores del momento a presionar a los otros homólogos no acudiendo a los Consejos de Ministros; se trata de la conocida como "crisis de la silla vacía», que se cerró -realmente en falso hasta el Acta Única Europea- a través del Compromiso de Luxemburgo de 30 de enero de 1966. Según éste, en algunas materias que venían decidiéndose por unanimidad, los Estados miembros se comprometían a tomar la decisión por mayoría cualificada (fórmula "sí, pero», típica en el mundo jurídico); ahora bien, a esta excepción podía sobrevenirle otra excepción (un nuevo "pero" al "sí, pero"), consistente en que se retornaría a la unanimidad cuando se invocase un "interés vital». La "trampa" de esta nueva "ley" (en realidad, "pacto de caballeros») radicaba en quién decidía cuándo mediaba ese interés vital, ofreciéndose una respuesta que desvirtuaba totalmente el compromiso, a saber, el propio Estado que lo invocaba, con lo que se llegó a la anécdota real de que, por ejemplo, Italia llegara a calificar como vital la longitud de los spaghetti.

En el caso de la mayoría cualificada, la ponderación de los votos tiene en cuenta el tamaño de la población de cada Estado miembro. En la Unión actual de los veinticinco, el artículo 205.2 del Tratado de la Comunidad Europea se vio afectado por las modificaciones introducidas a través del Tratado de Niza de cara a la Europa ampliada [en conexión con el artículo 3 -Disposiciones relativas a la ponderación de los votos en el Consejo- del Protocolo A anejo, y la Declaración 20.2 relativa a la ampliación de la Unión Europea], procediéndose a la siguiente ponderación: Alemania, Reino Unido, Francia e Italia 29; España y Polonia 27; Rumania 14; Países Bajos 13; Grecia, República Checa, Bélgica, Hungría y Portugal 12; Suecia, Bulgaria y Austria 10; Eslovaquia, Dinamarca, Finlandia, Irlanda y Lituania 7; Letonia, Eslovenia, Estonia, Chipre y Luxemburgo 4; y Malta 3. De tal manera que, ascendiendo el número total de votos a 345, para la toma de decisiones cualificadas se precisará al menos: o 258 votos que representen la votación favorable de la mayo- 
ría de los miembros cuando la propuesta proceda de la Comisión; o 258 votos que representen la votación favorable de dos tercios de los miembros; en ambos casos, cualquier miembro del Consejo puede solicitar que se compruebe que los Estados miembros que constituyen la mayoría cualificada representan como mínimo al $62 \%$ de la población total de la Unión pues, si se pusiere de manifiesto que esta condición no se cumple, la decisión en cuestión no será adoptada. Aun así, para compensar el peso prevalente de los intereses estatales en el Consejo y no reproducir episodios como la histórica "crisis de la silla vacía", con el Tratado de Niza se aumentó en casi una cincuentena el número de materias, señaladamente técnicas, en las que las decisiones pasarían a ser decididas por mayoría cualificada en lugar de por unanimidad ${ }^{15}$.

Por lo demás, dado que la ampliación de la Unión se produce de manera gradual, el Tratado de Niza incluyó una Declaración (la $n .^{\circ}$ 21) relativa al umbral de la mayoría cualificada y al número de votos de la minoría de bloqueo en una europea ampliada, con el siguiente tenor: «En la medida en que todos los estados candidatos que figuran en la lista incluida en la Declaración relativa a la ampliación de la Unión Europea no se hayan adherido todavía a la Unión cuando entren en vigor las nuevas ponderaciones de votos (1de enero de 2005), el umbral de la mayoría cualificada evolucionará en función del ritmo de las adhesiones, a partir de un porcentaje inferior al porcentaje actual hasta alcanzar un máximo del 73,4 por ciento. Cuando se hayan adherido todos los estados candidatos anteriormente mencionados, la minoría de bloqueo, en una Unión de 27, pasará a 91 votos y el umbral de mayoría cualificada resultante del cuadro que figura en la Declaración relativa a la ampliación de la Unión Europea será adaptado en consecuencia automáticamente». En realidad, estas complejas cláusulas emergen cuando se verifica una ampliación importante de la Unión, y así sucedió por ejemplo cuando ésta pasó de doce a quince Estados miembros, lo que precisó la adopción del Acuerdo de loannina de 29 de marzo de $1994^{16}$.

15 Sin embargo, en aspectos "sensibles" para diversos países se mantiene el derecho de veto. Es el caso de los asuntos sociales y de cohesión para España, los asuntos de fiscalidad para el Reino Unido, el fenómeno de la inmigración y el asilo en el caso alemán, o las cuestiones de libertad comercial en el terreno cultural y audiovisual para Francia.

16 Así, en la Unión Europea de los Quince, la distribución y peso específico de cada miembro del Consejo era la siguiente (artículo 205.2 del Tratado de la Comunidad Europa en su anterior redacción): Alemania, Francia, Italia y Reino Unido 10; España 8; Bélgica, Grecia, Países Bajos y Portugal 5; Austria y Suecia 4; Dinamarca, Irlanda y Finlandia, 3; y Luxemburgo 2. De suerte que, para la adopción de los acuerdos se requerían al menos: o 62 votos cuando debieran ser adoptados a pro- 
Si nos centramos ahora en el segundo vector mencionado, el mayor poder decisorio del Consejo se manifiesta en la circunstancia de que en él reside básicamente la competencia normativa general de la Unión, matizada justamente por los procedimientos codecisorios en los que interviene el Parlamento Europeo. En una primera etapa, el Parlamento Europeo sólo ostentaba un mero poder consultivo sobre las propuestas legislativas de la Comisión y, desgraciadamente, en ocasiones pretendió el Consejo hacer caso omiso incluso de dicha facultad parlamentaria, por lo que llegó a intervenir el Tribunal de Justicia para salvaguardarla. En particular, uno de los asuntos más interesantes sobre equilibrio de poderes en el seno de la Unión (caso S.A. Roquette Frères contra Consejo, de 29 de octubre de 1980), versó sobre ese derecho del Parlamento Europeo a ser consultado, anulándose el Reglamento controvertido del Consejo que había eludido ese importante trámite, con un lenguaje novedoso en aquel momento: "La consulta previa prevista para ello en (...) el Tratado es el medio que permite al Parlamento (...) tomar parte en el proceso legislativo de la Comunidad. Tal poder representa un factor esencial en el equilibrio institucional establecido por el Tratado. Aunque limitado, tal equilibrio refleja a nivel comunitario el principio fundamental democrático según el cual el pueblo debe participar en el ejercicio del poder a través de una asamblea legislativa» (apartado 33).

puesta de la Comisión; o 62 votos que a su vez representaren diez miembros como mínimo en los demás casos. A este respecto, cobraba interés la minoría de bloqueo, es decir, que elevándose a 87 el número total de votos y la mayoría cualificada a 62 (equivalente a un $71 \%$ ), bastaban 26 votos para bloquear una decisión; con ello, los cuatro grandes (o cinco, sin incluimos a España) no podían adoptar una decisión cualificada sin contar con otros Estados pequeños, en un difícil equilibrio entre proporción demográfica e integración territorial que favorecía o suponía sobrerrepresentación de los segundos, puesto que los grandes representaban más de la mitad de la población comunitaria. Estas dos variables siempre son objeto de controversia cuando se prevé una nueva ponderación propiciada por la adhesión de otros estados miembros, como se puso de manifiesto con el citado Acuerdo de loannina de 29 de marzo de 1994 adoptado por el Consejo de Ministros de Asuntos Exteriores con motivo de la preparación del Tratado de Adhesión de Austria, Finlandia, Noruega y Suecia, en que se fijaba la mayoría cualificada en 64 y la minoría de bloqueo en 27 votos (el referéndum negativo noruego produjo que se rebajara a los ya mencionados 62 y 26 , respectivamente); las tensiones fueron agudas hasta el punto de poner en peligro la adhesión de esos países para el 1 de enero de 1995, dado que los Ilamados países de la cohesión (España, Grecia, Irlanda y Portugal) no podían siquiera constituir una minoría de bloqueo al sumar sus votos (un total de 21), y en este sentido denunciaban un desequilibrio norte-sur en beneficio de los países nórdicos. 
El caso es que, a partir de 1987 con la entrada en vigor del Acta Única Europea, se reforzó el poder legislativo del Parlamento con la introducción del denominado procedimiento de cooperación (abocado a su desaparición por obsolescencia), mientras que tras la vigencia en 1993 del Tratado de Maastricht se amplió considerablemente dicho poder a través del nuevo procedimiento de codecisión (que en la práctica supone la posibilidad de veto por parte del Parlamento), habiendo ampliado las materias objeto de dicho procedimiento ( $y$, por tanto, el protagonismo del Parlamento) tanto el Tratado de Ámsterdam de 1997 como el Tratado de Niza de 2001 hasta configurarlo como el «procedimiento normal» o la "regla general»" 17 .

Finalmente, en el contexto del tercer vector mencionado, cabe recordar que, aun ostentando el Consejo las competencias ejecutivas más significativas, desde el punto de vista cuantitativo es la Comisión quien detenta mayores poderes de ejecución, ya a título propio, ya por atribución de esas competencias de ejecución por parte del Consejo. $Y$ ha sido precisamente en relación con este segundo aspecto en donde se ha suscitado la más conocida polémica, en el marco de la llamada "comitología». Ésta se instituyó mediante la Decisión 87/373/CEE del Consejo, de 13 de julio de 1987, por la que se establecen las modalidades del ejercicio de las competencias de ejecución atribuidas a la Comisión ("Decisión comitología»): así, los comités constituidos de conformidad con dicha Decisión asisten a la Comisión cuando ésta adopta medidas de ejecución en ejercicio de las facultades que le haya atribuido el Consejo. Más precisamente, el origen de los comités denominados de "comitología" se encuentra en el inicial artículo $145 \mathrm{del}$ Tratado de la Comunidad Europea (actualmente, artículo 202), que establece que el Consejo puede atribuir a la Comisión, respecto de los actos que el Consejo adopte, las competencias de ejecución de las normas que éste establezca; dichos comités, constituidos de conformidad con la Decisión comitología, están compuestos por representantes de los Estados miembros y presididos por un representante de la Comisión. Por tal razón, también la Comisión asume cierta responsabilidad

17 Por consiguiente, el procedimiento de codecisión (artículo 251 del Tratado de la Comunidad Europea), cuya generalización progresiva ha venido reduciendo correlativamente el déficit democrático de la Eurocámara, coloca en pie de igualdad a ésta y al Consejo, desembocando en la adopción de textos comunes por parte de ambas instituciones $y$, bajo la sombra del poder de veto que ostenta el Europarlamento pueden introducirse más fácilmente las enmiendas parlamentarias en las leyes comunitarias. Además, se prevé un Comité de Conciliación para desbloquear posibles divergencias del Parlamento con el Consejo y la Comisión, con el fin de no llegar a la solución del veto. 
en el funcionamiento de dichos comités, como se puso de manifiesto con la sentencia del Tribunal de Primera Instancia de 19 de julio de 1999 (asunto T-188/97, caso Rothmans International BV contra Comisión), mediante la que se anula la decisión de la Comisión de 30 de abril de 1997, por la que se deniega a la demandante el acceso a las actas del Comité del Código aduanero.

\subsection{Configuración y decurso históricos del Consejo Europeo}

\subsubsection{De las informales "cimas europeas" a la institucionalización del Consejo Europeo}

En el momento presente, es decir, con el Derecho de la Unión Europea vigente tras el Tratado de Niza, a diferencia del Consejo, que como se ha visto- tiene el rango de institución comunitaria compuesta por representantes ministeriales de los países miembros y ostenta poder de decisión, el Consejo Europeo es una institución política que se integra por los Jefes de Estado y/o de Gobierno de los Estados miembros (en la mayoría de casos, Jefes de Gobierno - al ser más extendido el sistema parlamentario-, excepto en casos de Ejecutivo bicéfalos efectivos como ocurre en Francia, en donde a veces no es sencilla la "cohabitación» entre Presidente de la República y Primer Ministro de distinto signo político) y carece formalmente de poder decisorio. En efecto, mientras en el Tratado constitucional de 2004 se confiere el rango de institución al Consejo Europeo, éste no puede según la normativa actual de la Unión adoptar actos de carácter legislativo o ejecutivo, sino sólo decidir sobre orientaciones políticas generales que, partiendo del "programa de actividad" o la "agenda" propuestos por el Gobierno que ostenta la Presidencia semestral rotatoria del Consejo, perfilan una especie de función general de dirección política gubernamental de la Unión que luego ha de ser concretada mediante actos jurídicos por las instituciones comunitarias. Dicho lo cual, la regulación básica y aislada del Consejo Europeo se establece en el vigente artículo 4 del Tratado de la Unión, en donde se señala de manera más precisa su composición "por los Jefes de Estado o de Gobierno de los Estados miembros, así como por el Presidente de la Comisión. Estarán asistidos por los Ministros de Asuntos Exteriores de los Estados miembros y por un miembro de la Comisión".

A decir verdad, más que de institución política, habría que hablar de reunión de los máximos mandatarios de cada Estado miembro pues, pese a constituir el actor de mayor peso político e influencia en los im- 
pulsos o retrocesos dados a la construcción europea (precisamente por su composición al más alto nivel), los tratados constitutivos no previeron su institucionalización, que sigue sin ser plena todavía. En tal dirección, para no paralizar la marcha a "pequeños pasos» en el camino integrador europeo, en la Cumbre de París de diciembre de 1974 se decidió que los máximos responsables de cada Estado miembro y el Presidente de la Comisión se reunieran regularmente, al menos una o dos veces cada semestre en el territorio del país que ostentara la Presidencia de turno de la Comunidad. Se ponían así las bases para firmar el acta de defunción de las anteriores "Cumbres europeas" (pese a que todavía se siga utilizando este vocablo en la jerga comunitaria y en medios de comunicación social) y dar nacimiento a los "Consejos Europeos" en aras a la profundización interna en el proceso integrador, aun cuando esos Consejos no gozaran de base constitucional ni legal (a semejanza de lo que ocurrió con la puesta en funcionamiento de la Cooperación Política Europea en 1972 para relanzar la política internacional de la Comunidad). De hecho, sólo con el Acta Única Europea se dio cobertura legal a la existencia del Consejo Europeo, mientras que habría que esperar al Tratado de la Unión Europea aprobado en Maastricht para fijar su composición y la previsión del número de reuniones al semestre.

Pero, en cualquier caso, hasta tanto no entre en vigor el Tratado constitucional de 2004, el Consejo Europeo sigue sin tener el rango de institución, funcionando en la práctica como una especie de Cámara confederal que utiliza como medio la cooperación intergubernamental para alcanzar fines integracionistas ${ }^{18}$ : consiguientemente, su no consagración como institución en el Derecho de la Unión Europea (a diferencia del Proyecto Herman de Constitución Europea de 1994, que ubicaba al Consejo Europeo como una de las cinco instituciones de la Unión —el Tribunal de Cuentas no llevaba aparejada tal naturaleza-) le permiten mayor margen de maniobra política, al quedar sus decisiones en principio al margen de la fiscalización del Tribunal de Justicia. Y, en última instancia, las tareas del Consejo Europeo son trasunto paradigmático de la tensión existente entre la dinámica integracionista y el método intergubernamental de construcción europea.

Realmente, aunque no se le haya otorgado el rango de institución de momento según la normativa vigente tras el Tratado de Niza y consecuentemente no adopte actos jurídicos formales, el Consejo Europeo

18 Morata, F.: La Unión Europea. Procesos, actores y políticas, Barcelona, Ariel, 1997, en especial, capítulo 6 («El Consejo Europeo»), p. 175. 
ha conocido cierta "institucionalización" o, si se prefiere, cierta permanencia en su funcionamiento. Así, el citado artículo 4 del Tratado de la Unión Europea estableció que se reunirá al menos dos veces al año, bajo la presidencia del Jefe de Estado o de Gobierno del Estado miembro que ejerza la Presidencia semestral del Consejo: sobre este aspecto singular, el Tratado de Niza incluyó una Declaración (la n. ${ }^{\circ} 22$ ) relativa al lugar de reunión de los Consejos Europeos en la que se dispone que "a partir de 2002, una reunión del Consejo Europeo por presidencia se celebrará en Bruselas. Cuando la Unión cuente con dieciocho miembros, todas las reuniones del Consejo Europeo se celebrarán en Bruselas». Desde luego, a medida que se amplía el número de países miembros y las políticas comunitarias adquieren mayor grado de desenvolvimiento y complejidad, las reuniones del Consejo Europeo van adquiriendo tintes más estables, dejando de ser el inicial foro de debate informal de dimensiones reducidas caracterizado como una inicial «prolongación o formación especial del Consejo de Ministros".

El mencionado artículo 4 del Tratado de la Unión Europea prescribe que el Consejo Europeo presente al Parlamento Europeo un informe después de cada una de sus reuniones, así como un informe escrito anual relativo a los progresos realizados por la Unión. Por consiguiente, tanto la Eurocámara (como máxima institución representativa) en cuanto al output, como la Comisión (como motor de integración) respecto al input, quedan asociados a la elaboración de los impulsos y orientaciones "constitucionales» lanzados por el Consejo Europeo. Indudablemente, el desarrollo de cada Consejo Europeo dependerá del talante político del Jefe de Estado o de Gobierno del país que ocupe la Presidencia semestral de la Unión, así como de las prioridades políticas que pretenda impulsar y plasmar en cada orden del día. Con esta finalidad, es habitual que con un año de antelación, al margen de suscitar un debate en el respectivo Parlamento nacional, ese leader estatal o gubernamental se desplace por las distintas capitales europeas para entrevistarse con sus homólogos (así como con el Presidente de la Comisión) e ir preparando y abonando el terreno a una futura negociación previamente consensuada, lo que en gran medida estará en función - como se advertía- de las "ambiciones" políticas (de la agenda) del Presidente de turno y del éxito que quiera conseguir con su Presidencia semestral.

Desde esta perspectiva, el ejercicio de la Presidencia semestral, no constituye sólo una oportunidad propicia para promocionar la imagen del país, sino que también es aprovechada por el Primer Ministro del país para efectuar propaganda positiva ante "su» electorado: pensemos en la Presidencia española del segundo semestre de 1995, que sirvió al 
partido (socialista) en el poder para obtener mejores resultados de los previstos en las elecciones generales anticipadas de marzo de 1996 (se habló entonces de "dulce derrota»); obviamente, Felipe González no quiso adelantarlas a Navidad de 1995 para que la Presidencia española de la Unión no fuera utilizada, en sentido contrario, por la oposición para poner en evidencia a un frágil Gobierno en funciones. Una percepción similar se suscitó con motivo de la celebración del Debate sobre el estado de la Nación de 2002 en el mes de julio (pese a ser período de inhabilidad parlamentaria), fecha elegida por el Gobierno de Aznar bajo el pretexto (admisible para algunos grupos de la oposición, refutado por otros que entendían que podía encontrarse hueco en el mes de mayo de 2002) del enorme trabajo que presupone la asunción de la Presidencia semestral de la Unión Europea.

Como es obvio, los Consejos Europeos de cierre de una Presidencia semestral que han concluido con las más importantes reformas "constitucionales" han adquirido mayor relieve: basta recordar, en especial, los Consejos Europeos de Maastricht de diciembre de 1991, de Ámsterdam de junio de 1997, de Niza de diciembre de 2000 o, más recientemente, de Tesalónica de junio de 2003, de Bruselas de junio de 2004 y de Roma de octubre de 2004 - los tres últimos referentes al Tratado constitucional de 2004-. Naturalmente, todos los países intentan ser "recordados" positivamente por alguna circunstancia exitosa en el ejercicio de "su» Presidencia semestral (así, en el Consejo Europeo de Madrid de diciembre de 1995, se cerró la Presidencia española dando nombre a la moneda única, el euro) y, de hecho, si en el turno rotatorio un país no está en condiciones de asumir exitosamente ese reto, puede llegar a darse el caso de renunciar o dejar pasar el turno, como ocurrió en su día con Portugal recién ingresada en las Comunidades Europeas. Por último, cabe indicar que el funcionamiento de cada Consejo Europeo se cierra formalmente con la publicación de las "Conclusiones de la Presidencia" como manifestación del consenso logrado por los Estados miembros (sin que normalmente medien votaciones), conclusiones que recogen una especie de "pacto de caballeros" y que llegan tras dos días de trabajo ${ }^{19}$.

19 El primer día se abre con un discurso del Presidente del Parlamento Europeo dirigido a los participantes en la "Cumbre europea», que va sucedido de una sesión plenaria y a puerta cerrada en la mañana del primer día; a lo largo de ese primer día se suceden discusiones entre los Jefes de Estado y de Gobierno y un gran contingente de expertos y asesores que intentan acercar posiciones entre las diversas delegaciones, aprovechando incluso las horas de restauración, sin perjuicio de las interrupciones que con el mismo espíritu pueda llevar a cabo el Presidente del Consejo Europeo (recordemos en el Consejo Europeo de Niza en diciembre de 


\subsubsection{Su diseño como máxima instancia política constituyente} de la Unión Europea

El Consejo Europeo tiene asignada como principal atribución en el artículo 4 del Tratado de la Unión la de dar a la Unión Europa "los impulsos necesarios para su desarrollo" y la de definir "sus orientaciones políticas generales"; dicho de otro modo, pone en marcha las principales iniciativas político-constitucionales y arbitra las cuestiones polémicas que se suscitan en la Unión Europea. Así, al margen de la parca base habilitante mencionada, se ha ido introduciendo paulatinamente una disciplina parcial en el Derecho de la Unión Europea. A título de ejemplo, el Consejo Europeo debe ser informado por el Consejo en el ámbito de la política económica y monetaria y, sobre la base de dicho informe, el Consejo Europeo "debatirá unas conclusiones sobre las orientaciones generales de las políticas económicas de los estados miembros y de la Comunidad" (artículo 99.2 del Tratado de la Comunidad Europea). Con carácter añadido, al Consejo Europeo debe remitirse por el Banco Central Europeo «un informe anual sobre las actividades del Sistema Europeo de Bancos Centrales y sobre la política monetaria del año precedente y del año en curso", informe que aquél ha de hacer llegar asimismo al Parlamento Europeo, al Consejo y a la Comisión (artículo 113.3 del Tratado de la Comunidad Europea). Además, en el marco de la política de empleo, «el Consejo y la Comisión prepararán un informe anual conjunto para el Consejo Europeo sobre la situación del empleo en la Comunidad y sobre la aplicación de las orientaciones para el empleo" (artículo 128.5 del Tratado de la Comunidad Europea).

Si esto es así en el ámbito de la integración, en lo que afecta cabalmente a la cooperación intergubernamental, el Consejo Europeo definirá orientaciones generales en las que se basará el Consejo para tomar las decisiones necesarias para diseñar y ejecutar la política exterior y de seguridad común (artículo 13.3 del Tratado de la Unión Europea), orientaciones que también regirán respecto a la Unión Europea Occidental en aquellos asuntos en los que la Unión recurra a ella; y, en este mismo ámbito, el Consejo puede pedir, por mayoría cualificada, que un asunto

2000 los numerosos recesos de la Presidencia francesa). El segundo día comienza asimismo con una sesión plenaria en la que se examina el borrador de las conclusiones del primer día de trabajo (para cuya elaboración ha podido quedarse trabajando hasta altas horas de la noche los funcionarios de la Presidencia y de la Secretaría del Consejo) y se sigue discutiendo para llegar a un acuerdo conjunto, concluyendo con un almuerzo. 
en el que un Estado miembro alegue por motivos importantes y explícitos de política nacional la intención de oponerse a una acción común, posición común o cualquier otra decisión basada en una estrategia común sobre seguridad y defensa exterior, «se remita al Consejo Europeo para que decida al respecto por unanimidad" (artículo 23.2 del Tratado de la Unión). Por ende, nos hallamos en este último supuesto ante una competencia no sólo de información, sino netamente decisoria en manos del Consejo Europeo. Lo mismo sucede con la potestad de elegir al Presidente de la Comisión, que la ejerce de acuerdo con el Parlamento Europeo (artículo 214.2 del Tratado de la Comunidad Europea).

Al margen de las atribuciones que acaban de explicitarse, las demás competencias del Consejo Europeo revisten un carácter lo suficientemente amplio o difuso como para permitirle una conducción asistida o adaptable de las prioridades de la construcción europea en cada momento. De hecho, en el Consejo Europeo que cerró la Presidencia británica de la Unión en el primer semestre de 1977, la Declaración de Londres procedió a un intento de sistematización de esas competencias a través de un elenco igualmente amplio o difuso, distinguiendo tres "tipos de discusiones" susceptibles de plantearse en aquél ${ }^{20}$ : el primero consiste en el intercambio informal de puntos de vista; el segundo radica en la fijación de objetivos o la adopción de decisiones destinadas a materializarse en textos legales; y el tercero se concreta en el tratamiento de temas difícilmente abordables en niveles inferiores. Este diseño abstracto de las atribuciones del Consejo Europeo se ha ido perfilando mediante la experiencia, lo que ha llevado a distinguir en la doctrina cuatro grandes bloques competenciales ${ }^{21}$ :

- De un lado, el impulso de las cuestiones constitucionales e institucionales, es decir, las que perfilan al Consejo Europeo como máxima instancia política constituyente de la Unión. Entre ellas, descuella el objetivo de la unión política en la agenda de cada Presidencia semestral de turno, con reformas institucionales de envergadura como la que condujo al Tratado de Ámsterdam tras el Consejo Europeo de junio de 1997, o con las sucesivas ampliaciones como la prevista en el Tratado de Niza tras el Consejo Europeo de diciembre de 2000, sin olvidar la discusión sobre la ubicación de las sedes comunitarias en Consejos Europeos como el de Edimburgo en diciembre de 1992; y,

${ }^{20}$ Sigo en este punto de la exposición a Morata, F.: La Unión Europea. Procesos, actores y políticas, ya cit., pp. 175-190.

21 Ibidem. 
señaladamente, los ya citados Consejos constituyentes de Tesalónica de junio de 2003, de Bruselas de junio de 2004, y de Roma de octubre de 2004.

- De otro lado, el avance de las cuestiones económicas, financieras y monetarias En este ámbito, el Consejo Europeo de Essen de diciembre de 1994 erigió la política de empleo en tarea prioritaria de la Unión, mientras el Consejo Europeo de Madrid en junio de 1989 comportó la puesta en marcha del proceso hacia la moneda única, que fue bautizada con la denominación de "euro" en otro Consejo Europeo de Madrid en diciembre de 1995 fijándose el calendario de su puesta en circulación efectiva.

- En tercer lugar, la dinamización de las relaciones exteriores de la Unión. No sólo las de tipo comercial —sin perjuicio de los sucesivos Convenios de cooperación al desarrollo, en el Consejo Europeo de Copenhague en junio de 1993 se otorgó el estatuto de asociado a los PECOs, en el de Madrid de junio de 1995 se suscribió un acuerdo de asociación comercial con el grupo de MERCOSUR, y en el de Barcelona de marzo de 2002 estuvo presente el conflicto con Estados Unidos por la "guerra del acero" sometida a la OMC a causa de la fijación abusiva de los aranceles por parte estadounidense-, sino también las de carácter político - reconducidas al marco de la PESC, que ha mostrado sus insuficiencias ante el rol preponderante de Estados Unidos en conflictos intraeuropeos como la guerra en los Balcanes a partir de 1991-.

- Y, en cuarto término, el relanzamiento de las políticas internas. Lo que casi siempre guarda conexión con el reparto de fondos comunitarios, como ocurrió con la reforma del Presupuesto comunitario para dar respuesta a la PAC y a la financiación de otras políticas internas -en el Consejo Europeo de Bruselas de junio de 1988 se aprobó el "Paquete Delors I", mientras en el de Edimburgo de diciembre de 1992 se dio el visto bueno al «Paquete Delors II" - , o con la creación de un nuevo Fondo Estructural para la Pesca y el Fondo de Cohesión para financiación del medio ambiente y redes transeuropeas -Consejo Europeo de Maastricht de diciembre de 1991-, o con la potenciación de "nuevos espacios europeos" (de "justicia» para luchar más eficazmente contra el terrorismo con la rápida introducción de la orden europea de detención y entrega o euroorden y contra la inmigración ilegal reforzando el control en las fronteras exteriores, o el "cielo único europeo" para mayor seguridad en la na- 
vegación aérea tras los atentados del 11 de septiembre de 2001) 22 y "nuevas políticas liberalizadoras» (en materia de transportes, energía, finanzas o educación) - Consejo Europeo de Barcelona de marzo de 2002-.

\section{LA CONSTITUCIONALIZACIÓN DE EUROPA A TRAVÉS DE LA CONSTITUCIONALIZACIÓN DEL CONSEJO}

\subsection{Un nuevo reparto de poder en el seno del Consejo de Ministros}

Antes de entrar a analizar el nuevo reparto de poder en el Consejo de Ministros, conviene reiterar que el Tratado Constitucional vuelve a recuperar la denominación inicial de "Consejo de Ministros" (artículo I-23) que había sido abandonada con el Tratado de Maastricht de 1992. Así, el mencionado artículo I-23 contiene la regulación constitucional básica del Consejo de Ministros, de manera que recuerda su peso máximo decisorio como colegislador junto al Parlamento Europeo (apartado 1 ) $^{23} \mathrm{y}$,

${ }^{22}$ Efectivamente, algunos Consejos Europeos se han visto profundamente influidos por la situación internacional, como ocurrió en los celebrados bajo Presidencia belga en el segundo semestre de 2001, marcados por los atentados terroristas del 11 de septiembre de dicho año en Estados Unidos, que motivó poner el énfasis en las medidas antiterroristas (con la "euroorden" como objetivo más emblemático). El mismo ambiente internacional marcó los Consejos Europeos celebrados bajo la Presidencia española en el primer semestre de 2002, marcados por el fracaso del plan saudí de paz para Oriente Próximo y la acentuación del conflicto entre israelíes y palestinos; por lo demás, la delegación española anfitriona pretendió introducir alguna innovación digna de constituir precedentes positivos, como las reuniones paralelas (al Consejo Europeo de Barcelona de marzo de 2002, concretamente) de Consejos sectoriales con los interlocutores sociales adecuados. Prosiguiendo en relación con el funcionamiento del Consejo Europeo, la Presidencia española de 2002 ilustra la tipología de los que suelen celebrarse, dado que no todos tienen la misma periodicidad: así las cosas, los Consejos ordinarios se celebran en junio y en diciembre de cada año (esto es, como cierre y balance de la Presidencia semestral) normalmente en la capital del país concernido (así sucedió con el Consejo Europeo de Madrid de diciembre de 1995, aunque no con el Consejo Europeo de Sevilla de junio de 2002, siendo ambos los que cerraron sendas Presidencias semestrales españolas), mientras los extraordinarios o especiales (como el de Barcelona de 15-16 de marzo de 2002) carecen de fecha prefijada de manera sistemática y tienen lugar en otras ciudades de dicho país.

${ }^{23}$ Según el apartado 1 del artículo I-23 del Tratado constitucional: «El Consejo ejercerá conjuntamente con el Parlamento Europeo la función legislativa y la función presupuestaria. Ejercerá funciones de definición de políticas y de coordinación, en las condiciones establecidas en la Constitución". 
acorde con la nueva denominación, reitera que «el Consejo estará compuesto por un representante de cada Estado miembro, de rango ministerial, facultado para comprometer al Gobierno del Estado miembro al que represente y para ejercer el derecho a voto" (apartado 2).

Sobre este segundo extremo, ha de repetirse que ni la denominación ni el inciso "rango ministerial" constituyen obstáculo para entender que con dicho rango puedan participar en el Consejo representantes gubernamentales de las entidades infraestatales. Por tal motivo, no es extraño que el debate sobre el particular haya continuado en España: particularmente, en lo relativo a la participación de las Comunidades Autónomas en el Consejo, cabe señalar como una de las últimas realizaciones en nuestro país el Acuerdo de 9 de diciembre de 2004 de la Conferencia de Asuntos Relacionados con las Comunidades Europeas sobre formaciones del Consejo de la Unión Europea, que ofrece la posibilidad de que un miembro del Consejo de Gobierno de una Comunidad Autónoma acuda, junto con el representante de la Administración del Estado con rango de Ministro, a las reuniones del Consejo de la Unión en representación de todas las Administraciones Autonómicas. De manera más precisa, el Acuerdo propicia el recurso a este sistema de representación autonómica en lo que atañe a las cuatro siguientes formaciones del Consejo de la Unión: Empleo, Política Social, Sanidad y Consumidores (incluido Turismo); Agricultura y Pesca; Medio Ambiente; Educación, Juventud y Cultura ${ }^{24}$.

El mencionado artículo I-23 viene completado por el apartado 3, con el que se pretende dejar atrás definitivamente - máxime en nuestra Europa ampliada - el lastre de la posibilidad de veto o de bloqueo generada por la regla de la unanimidad, generalizándose el procedi-

${ }^{24}$ Ahora bien, el alcance de este Acuerdo y la consiguiente participación regional en esas formaciones del Consejo debe matizarse, por cuanto no es automática, dado que para que esa participación sea efectiva es preciso que la Conferencia Sectorial competente en la materia determine al inicio de cada presidencia semestral del Consejo una serie de variables nada desdeñables, a saber: de un lado, cuáles serán los asuntos en los cuales sea susceptible de aplicación la representación autonómica directa, a la vista de los asuntos incluidos en las reuniones previstas en el programa de actividad de la presidencia semestral; de otro lado, quién será el representante autonómico que asuma la coordinación de las distintas Comunidades Autónomas en los asuntos en donde se haya acordado acudir a esa representación regional, con el objeto de alcanzar una posición común autonómica y acordar ésta con la de la Administración del Estado; por tanto, ese representante autonómico consensuado formará parte de la delegación española en las reuniones de las formaciones referidas del Consejo como miembro del pleno derecho. 
miento de mayoría cualificada ${ }^{25}$. Dicho esto, cuando se alude al nuevo reparto de poder en el presente epígrafe, cabe reflexionar en un doble frente: por una parte, el Tratado constitucional se ha hecho eco explícitamente de la creciente complejidad de los asuntos europeos como consecuencia lógica de la paulatina transferencia del ejercicio de competencias soberanas, de modo que ha incluido un precepto sobre las formaciones más importantes del Consejo (reparto de poder ad intra artículo I-24-); y, por otra parte, aunque con el Tratado de Niza pareció haberse cerrado el reparto de poder entre los Estados miembros, con el Tratado constitucional se produjo un nuevo y polémico episodio de reponderación de votos (reparto de poder ad extra -artículo l-25-). Repasemos brevemente ambos aspectos.

En lo referente al primer aspecto, resulta suficientemente ilustrativa la trascripción del artículo l-24 del Tratado constitucional, que bajo la rúbrica Formaciones del Consejo de Ministros presenta el siguiente contenido: «1. El Consejo se reunirá en diferentes formaciones. 2. El Consejo de Asuntos Generales velará por la coherencia de los trabajos de las diferentes formaciones del Consejo. Preparará las reuniones del Consejo Europeo y garantizará la actuación subsiguiente, en contacto con el Presidente del Consejo Europeo y la Comisión. 3. El Consejo de Asuntos Exteriores elaborará la acción exterior de la Unión atendiendo a las líneas estratégicas definidas por el Consejo Europeo y velará por la coherencia de la actuación de la Unión. 4. El Consejo Europeo adoptará por mayoría cualificada una decisión europea por la que se establezca la lista de las demás formaciones del Consejo. 5. Un Comité de Representantes Permanentes de los Gobiernos de los Estados miembros se encargará de preparar los trabajos del Consejo. 6. El Consejo se reunirá en público cuando delibere y vote sobre un proyecto de acto legislativo. Con este fin, cada sesión del Consejo se dividirá en dos partes, dedicadas respectivamente a las deliberaciones sobre los actos legislativos de la Unión y a las actividades no legislativas. 7. La presidencia de las formaciones del Consejo, con excepción de la de Asuntos Exteriores, será desempeñada por los representantes de los Estados miembros en el Consejo mediante un sistema de rotación igual, de conformidad con las condiciones establecidas por una decisión europea del Consejo Europeo. El Consejo Europeo se pronunciará por mayoría cualificada».

En especial, la figura del Consejo de Asuntos Generales pretende superar la tendencia natural de cada Consejo sectorial de elaborar políticas propias y ganar mayor autonomía, lo cual ha generado graves

${ }^{25}$ A tenor del artículo l-23.3 del Tratado constitucional, «el Consejo se pronunciará por mayoría cualificada, excepto cuando la Constitución disponga otra cosa». 
contradicciones, sobre todo entre la política agraria común, la política de asuntos exteriores y la política presupuestaria. Se mencionan expresamente, por ende, los dos Consejos sectoriales más importantes para dotar de coherencia a la acción comunitaria, recuperándose con un organigrama bifocal el clásico papel de coordinación del "Consejo General» integrado por los Ministros de Asuntos Exteriores, considerados éstos como los "principales" representantes de cada país miembro. En cualquier caso, la toma de decisiones en el seno del Consejo requiere amplias dosis de talante negociador, asegurado especialmente por quien ocupa la Presidencia semestral, bajo fórmulas que van desde el más fluido "tour de table» en el que cada delegación estatal hace brevemente explícita su postura, hasta las reuniones restringidas o superrestringidas o incluso a dos bandas (entre el Presidente y cada uno de sus colegas de manera bilateral —la conocida como "técnica del confesionario" - ); negociaciones estas segundas en las que juega un papel nada desdeñable la mediación de los asesores ministeriales, de los representantes permanentes y de la propia Secretaría General. Sin olvidar, por último, que para limar eventuales asperezas insalvables o irreconciliables en las negociaciones, se ha ido consolidando la dinámica del "package deal", esto es, un paquete de acuerdos que satisfaga los intereses principales de cada país miembro, siendo paradigmáticos los "paquetes Delors I y II" en materia presupuestaria.

En lo atinente al segundo aspecto apuntado, el artículo l-25 del Tratado constitucional, bajo la rúbrica Definición de la mayoría cualificada en el Consejo Europeo y en el Consejo se hace eco del débil consenso alcanzado en la negociación "constituyente», en estos términos: "1. La mayoría cualificada se definirá como un mínimo del 55\% de los miembros del Consejo que incluya al menos a quince de ellos y represente a Estados miembros que reúnan como mínimo el $65 \%$ de la población de la Unión. Una minoría de bloqueo estará compuesta al menos por cuatro miembros del Consejo, a falta de lo cual la mayoría cualificada se considerará alcanzada. 2. No obstante lo dispuesto en el apartado 1, cuando el Consejo no actúe a propuesta de la Comisión o del Ministro de Asuntos Exteriores de la Unión, la mayoría cualificada se definirá como un mínimo del $72 \%$ de los miembros del Consejo que represente a Estados miembros que reúnan como mínimo el $65 \%$ de la población de la Unión. 3. Los apartados 1 y 2 se aplicarán al Consejo Europeo cuando se pronuncie por mayoría cualificada. 4. El Presidente del Consejo Europeo y el Presidente de la Comisión no participarán en las votaciones del Consejo Europeo". Esta nueva ponderación del voto en el seno del Consejo y del Consejo Europeo, una vez verificada la entrada en vigor del Tratado constitucional, surtirá efectos a partir del 1 de no- 
viembre de 2009, de conformidad con el artículo 2.1 del Protocolo n. ${ }^{\circ}$ 34, anejo al Tratado, sobre las disposiciones transitorias relativas a las instituciones y órganos de la Unión.

Sin necesidad en esta sede de detenerse en operaciones aritméticas, es sabido que las previsiones del Tratado constitucional han producido una ostensible modificación del peso político de los Estados miembros en el seno del Consejo en comparación con la situación vigente reflejada en el Tratado de Niza; algunos de esos países miembros - como ha sido el caso especial de España- han salido perjudicados desde este punto de vista, habiendo obtenido una compensación «institucional» que no es equiparable, con la asignación de cuatro diputados europeos más respecto a los inicialmente previstos en el proyecto de Tratado constitucional. En efecto, en el delicado equilibrio alcanzado en el texto constitucional europeo, se ha reducido el umbral de la mayoría cualificada, complicando la obtención de la minoría de bloqueo a todos los Estados distintos de los cuatro grandes (Alemania, Francia, Italia y Reino Unido). Más aún, la fórmula inicial propuesta por la Convención presidida por Giscard d'Estaing todavía resulta más onerosa para los Estados de menor tamaño desde la perspectiva de la denominada "cláusula de verificación demográfica» ${ }^{26}$.

Ya se dijo en el primer epígrafe de este trabajo que el nuevo reparto de poder en el seno del Consejo cobró una fuerza nada despreciable en la campaña electoral del referéndum español de 20 de febrero de 2005 relativo al Tratado constitucional ${ }^{27}$. En ese mismo ambiente, el anterior

${ }^{26}$ Concretamente, los apartados 1 y 2 del artículo I-24 de la Parte I del Proyecto de Tratado constitucional presentaba esta redacción: «1. Cuando el Consejo Europeo o el Consejo de Ministros actúen por mayoría cualificada, ésta se definirá como una mayoría de Estados miembros que represente al menos las tres quintas partes de la población de la Unión. 2. Cuando la Constitución no exija que el Consejo Europeo o el Consejo de Ministros actúen a partir de una propuesta de la Comisión, o cuando el Consejo Europeo o el Consejo de Ministros no actúen por iniciativa del Ministro de Asuntos Exteriores de la Unión, la mayoría cualificada consistirá en dos tercios de los Estados miembros que representen al menos las tres quintas partes de la población de la Unión». Con esta fórmula, Alemania pasaba prácticamente a duplicar su porcentaje de votos (del $9 \%$ en Niza al 17\% que le concedía la Convención), un porcentaje menor los otros tres grandes Estados (el Reino Unido del 9\% al 12,3\%, Francia del $9 \%$ al $12,2 \%$, e Italia del $9 \%$ al 11,9\%). Los otros Estados reducían su porcentaje ponderado: así, los intermedios como España y Polonia pasaban del 8,4\% en Niza al 8,1 y $8 \%$ respectivamente (los porcentajes señalados se han calculado sobre la base de las Actas de Adhesión, sin tener en cuenta a Bulgaria y Rumania).

27 Con tono crítico, léase Vivancos Comes, M., y BAS SoRIA, J. J.: «El inacabado debate sobre las reglas decisorias en el Consejo (a vueltas con el índice de poder de España en la Unión)", en la obra colectiva de tres tomos Comentarios a la Consti- 
Gobierno presidido por José María Aznar optó por dar publicidad internacional a través de internet y en inglés a la posición española en torno al nuevo reparto de poder en el seno del Consejo, con objeto de justificar su oposición al proyecto constitucional europeo ${ }^{28}$. Este proceder no debe extrañar, puesto que no es más que el reflejo de la incapacidad demostrada por los responsables gubernamentales de todos los países miembros, de convencerse ellos mismos y de persuadir a los ciudadanos de estar embarcados en un proyecto común, cuando lo cierto es que, a la hora de la verdad, cada Estado miembro sigue defendiendo sus propios intereses, no siempre fáciles de conciliar con una decidida política integradora ${ }^{29}$; expresado de otra manera, la crítica esencial radica en la incapacidad para ofrecer una "fundamentación constitucional del proceso de construcción europea» ${ }^{30}$.

\subsection{La constitucionalización de la figura del Ministro europeo de asuntos exteriores como ministro "bicéfalo»}

La inclusión en el Tratado constitucional de la figura del Ministro de Asuntos Exteriores de la Unión constituye una las novedades más importantes del proceso de constitucionalización de Europa (artículo I-28):

tución Europea (dir. por E. Álvarez Conde y V. Garrido Mayol), libro I, Valencia, Tirant lo Blanch/Consejo Jurídico Consultivo de la Comunidad Valenciana, 2004, p. 617: «La apertura de un proceso constituyente europeo no ha sabido conectar con el sentimiento de una ciudadanía europea, y probablemente haya que imputar esta frustración a unas negociaciones en las cuales los intereses nacionales y las correspondientes posiciones relativas de poder han constituido el discurso predominante. En el caso español, y a falta todavía de estimaciones demoscópicas, podemos aventurar que el contenido constituyente que mayor repercusión social tiene es, sin duda, el referido a los votos asignados a cada país en el proceso de toma de decisiones".

${ }^{28}$ Puede leerse una extensa motivación de dicha postura en la dirección de internet: http://www.realinstitutoelcano.org/analisis/354.asp (Fundación Real Instituto Elcano, Madrid, 2005), bajo el título "Spain and the Intergovernmental Conference: the arguments in favour of retaining Nice», ARI N. ${ }^{\circ}$ 125/2003 - Análisis, Source: Spanish Ministry of Foreign Affairs (30/10/2003).

${ }^{29}$ Cfr. Alegre Martínez, M. A.: "La búsqueda de un modelo organizativo para la Unión Europea: el papel de los ciudadanos", en el colectivo El futuro de Europa a debate (Actas del Congreso internacional celebrado en Valladolid los días 17, 18 y 19 de septiembre de 2002 -coord. por A. Calonge Velázquez-), Instituto de Estudios Europeos, Universidad de Valladolid, 2003, pp. 67-82, en concreto p. 71.

30 Tajadura Tejada, J.: "La crisis de la Constitución en el proceso de integración europea", Revista de Derecho Político, n. ${ }^{\circ}$ 53, 2002, p. 268. 
en la actualidad sigue llamándose Alto Representante, aunque es considerado Ministro de Asuntos Exteriores in pectore con el apoyo de todos los Estados miembros de la Unión. Según el apartado 1 de este precepto, el Ministro de Asuntos Exteriores de la Unión es nombrado por el Consejo Europeo por mayoría cualificada, con la aprobación del Presidente de la Comisión, pudiendo el Consejo Europeo poner fin a su mandato por el mismo procedimiento. Su cometido más característico se establece en el apartado 2 del citado artículo l-28 del Tratado Constitucional, a tenor del cual «el Ministro de Asuntos Exteriores de la Unión estará al frente de la política exterior y de seguridad común de la Unión. Contribuirá con sus propuestas a elaborar dicha política y la ejecutará como mandatario del Consejo. Actuará del mismo modo en relación con la política común de seguridad y defensa».

Ahora bien, seguramente lo más destacado de la nueva figura del Ministro europeo de Asuntos Exteriores sea su naturaleza bicéfala, si reparamos en las otras funciones básicas que se le atribuyen: por un lado, según el apartado 3 del reiterado artículo l-28, "presidirá el Consejo de Asuntos Exteriores"; mientras, por otro lado, conforme al apartado 4 del mismo precepto, "será uno de los Vicepresidentes de la Comisión. Velará por la coherencia de la acción exterior de la Unión. Se encargará, dentro de la Comisión, de las responsabilidades que incumben a la misma en el ámbito de las relaciones exteriores y de la coordinación de los demás aspectos de la acción exterior de la Unión. En el ejercicio de estas responsabilidades dentro de la Comisión, y exclusivamente por lo que respecta a las mismas, el Ministro de Asuntos Exteriores de la Unión estará sujeto a los procedimientos por los que se rige el funcionamiento de la Comisión en la medida en que ello sea compatible con los apartados 2 y $3 »$. En síntesis, su caracterización bicéfala significa que el Ministro de Asuntos Exteriores de la Unión es, al tiempo, presidente de una de las formaciones del Consejo y uno de los vicepresidentes de la Unión.

Así las cosas, su naturaleza bifronte coloca al Ministro de Asuntos Exteriores en una posición idónea para tender puentes o flexibilizar tensiones entre el Consejo y la Comisión. La cuestión no es baladí. Por poner sólo un ejemplo, una de las nuevas categorías de actos jurídicos previstos por el Tratado constitucional, concretamente los reglamentos europeos delegados (artículo I-36), habrán de ser diseñados sin perder de vista problemáticas parangonables que han aflorado en el seno de la Unión, como ha sido el caso de la ya mencionada "comitología". Como es conocido, a la primera "Decisión comitología" de 1987 sucedió una segunda, concretamente la Decisión 1999/468/CE del Consejo, por la que se establecen los procedimientos para el ejercicio de las competencias 
de ejecución atribuidas a la Comisión. Sobre el alcance de esta segunda Decisión se ha pronunciado la Justicia comunitaria: así, por citar un supuesto reciente, en la sentencia del Tribunal de Justicia de 12 de julio de 2005 (dictada en asuntos acumulados C-154/04 y C-155/04, sobre el alcance de la Directiva 2002/46/CE, relativa a los complementos alimenticios comercializados en calidad de productos alimenticios y presentados como tales), al margen del fondo del asunto, la cuestión controvertida de interés en lo que afecta a nuestro estudio es que se suscitó nuevamente el alcance del reiterado peso específico del Consejo a través del recurso a la "comitología", y que esta práctica ha venido avalada una vez más por la jurisprudencia comunitaria ${ }^{31}$.

\subsection{El nuevo cariz institucional del Consejo Europeo}

Como se anticipó, el Tratado constitucional atribuye el rango de institución al Consejo Europeo (artículo l-19). Ello no obstante, viene en esencia a positivizar los rasgos que ya en la actualidad le caracterizan, constituyendo una de las novedadas más destacadas la pretensión de dotarle de mayor permanencia (mayor grado de institucionalización, si se quiere) preceptuando la necesaria celebración de una reunión trimestral en lugar de la actual semestral. Basta para comprobar tal afirmación acudir al contenido del artículo l-21 del Tratado constitucional, en virtud del cual: «1. El Consejo Europeo dará a la Unión los impulsos necesarios para su desarrollo y definirá sus orientaciones y prioridades políticas generales. No ejercerá función legislativa alguna. 2. El Consejo Europeo estará compuesto por los Jefes de Estado o de Gobierno de los Estados miembros, así como por su Presidente y por el Presidente de la Comisión. Participará en sus trabajos el Ministro de Asuntos Exteriores de la Unión. 3. El Consejo Europeo se reunirá trimestralmente por convocatoria de su Presidente. Cuando el orden del día lo exija, los miembros del Consejo Europeo podrán decidir contar, cada uno de ellos, con la asistencia de un ministro y, en el caso del Presidente de la Comisión, con la de un miembro de la Comisión. Cuando la situación lo exija, el Presidente convocará una reunión extraordinaria del Consejo

31 Según el apartado 78 de dicha sentencia, el procedimiento de comitología "trata de conciliar las exigencias de eficacia y de flexibilidad que conlleva la necesidad de adaptar y de actualizar regularmente diversos aspectos de la legislación comunitaria a la luz de la evolución de las concepciones científicas en materia de protección de la salud o de seguridad de las personas, por una parte, y el respeto de las competencias respectivas de las instituciones comunitarias, por otra». 
Europeo. 4. El Consejo Europeo se pronunciará por consenso, excepto cuando la Constitución disponga otra cosa».

El nuevo cariz institucional del Consejo Europeo podría caracterizarse de "constitucional" o "constituyente" si, cuanto menos, ponemos el punto de mira en el peso fundamental que se le otorga en el procedimiento de revisión ordinario del propio Tratado constitucional (artículo IV-443). En definitiva, lo que persigue esta disposición constitucional europea no es otra cosa que institucionalizar un cauce por medio del cual se articule la participación combinada del Consejo Europeo (en función culminante de Conferencia intergubernamental) y de una Convención similar a la presidida por Giscard d'Estaing o, con anterioridad, a la presidida por Herzog. Pues, de sobra conocida ha sido la crítica vertida sobre el proceso seguido en la elaboración del Tratado constitucional, que formalmente no se ha adecuado a los procedimientos de reforma establecidos en los Tratados comunitarios (en especial, el procedimiento de reforma normal $\mathrm{u}$ ordinario prescrito en el artículo 48 del Tratado de la Unión Europea). Dicho de otro modo, si con la Convención presidida por Giscard d'Estaing (simuladamente "constituyente") se ha pretendido reflejar un cierto halo de legitimidad popular ( en nombre de los ciudadanos» ${ }^{32}$ ), lo bien cierto es que esa Convención no constituye un mecanismo previsto jurídicamente en los Tratados comunitarios para la reforma de éstos, por mucho -insistimosque tanto esta Convención presidida por Giscard d'Estaing como la Convención de la Carta de Niza presidida por Herzog hayan seguido un procedimiento más o menos transparente y participativo. Estaríamos, pues, ante una especie de procedimiento, si no «ilegal (al no haberse producido una ruptura jurídica material, sino un "plausible" vicio procedimental), sí al menos «alegal»»33.

32 Con similar filosofía, la disposición que sirve de pórtico al Tratado constitucional (el artículo I-1, que lleva por rúbrica Creación de la Unión) establece en su apartado 1 que «la presente Constitución, que nace de la voluntad de los ciudadanos y de los Estados de Europa de construir un futuro común, crea la Unión Europea».

33 Esta catalogación, junto a otras experiencias de reforma constitucional, pueden encontrarse en trabajos de PACE, A.: "La 'naturale' rigidità delle costituzioni scritte», en Giurisprudenza Costituzionale, 1993, pp. 4085 y ss. (trad. esp. "La 'natural' rigidez de las constituciones escritas", en PACE, A., Y VARELA, J.: La rigidez de las constituciones escritas, Madrid, CEC, 1995, pp. 11 y ss.), o "In difesa della 'naturale' rigidità delle costituzioni scritte», en Giurisprudenza Costituzionale, 1995, pp. 1209 y ss. (trad. esp. «En defensa de la 'natural' rigidez de las constituciones escritas", en la obra anteriormente citada, pp. 115 y ss.); más recientemente, puede acudirse asimismo, entre otras contribuciones, a las dos siguientes monografías de PACE, A.: La causa della rigidità costituzionale, Padova, Cedam, 1996, y Potere costituente, rigidità costituzionale, autovincoli legislativi, Padova, Cedam, 1997.

(C) UNED. Revista de Derecho Político 


\subsection{El Presidente del Consejo Europeo como Presidente de la Unión Europea}

Junto a la creación de la figura del Ministro de Asuntos Exteriores de la Unión, la institucionalización del Presidente del Consejo Europeo, como parte de éste, constituye la otra gran novedad orgánica de mayor envergadura (incluso, simbólica) del Tratado constitucional ${ }^{34}$. El Presidente del Consejo Europeo, cuyo mandato es incompatible con todo mandato nacional, es elegido por un período de dos años y medio, renovable una sola $v^{2} z^{35}$. El Tratado constitucional le dedica una disposición específica (artículo I-22), queriendo realzar su entidad autónoma como una especie de "Presidente de la Unión Europea». Con este espíritu, el apartado 2 del citado artículo l-22 dispone que «el Presidente del Consejo Europeo asumirá, en su rango y condición, la representación exterior de la Unión en los asuntos de política exterior y de seguridad común, sin perjuicio de las atribuciones del Ministro de Asuntos Exteriores de la Unión".

$Y$ es que, hasta ahora, nos resultaba difícil identificar, no sólo en términos jurídico-políticos sino asimismo en clave de conciencia ciudadana, quién era el Presidente de la Unión, título que parecían compartir el Presidente de la Comisión como cargo permanente y el Primer ministro que ocupaba el cargo de Presidente semestral de turno de la Unión. Por otra parte, el citado apartado 2 del artículo l-22 perfila el cometido del Presidente del Consejo Europeo estableciendo el elenco de sus funciones básicas, de suerte que: «a) presidirá e impulsará los trabajos del Consejo Europeo; b) velará por la preparación y continuidad de los trabajos del Consejo Europeo, en cooperación con el Presidente de la Comisión y basándose en los trabajos del Consejo de Asuntos Generales; c) se esforzará por facilitar la cohesión y el consenso en el seno del Consejo Europeo; d) al término de cada reunión del Consejo Europeo, presentará un informe al Parlamento Europeo".

\footnotetext{
${ }^{34}$ Así lo ha destacado SÁnChEZ NAVARRo, A.: "El Consejo Europeo», en la obra colectiva de tres tomos Comentarios a la Constitución Europea, ya cit., p. 848: la creación de la figura del Presidente del Consejo Europeo presenta tal magnitud que "explica, lógicamente, y puede justificar» los "recelos de otras instituciones comunitarias, de mayor raigambre, pero cuya 'visibilidad' se verá, sin dudas, considerablemente afectada, y reducida, al lado de esta nueva figura".

${ }_{35}$ El apartado 1 del artículo I-22 del Tratado constitucional establece que «el Consejo Europeo elegirá a su Presidente por mayoría cualificada para un mandato de dos años y medio, que podrá renovarse una sola vez. En caso de impedimento o falta grave, el Consejo Europeo podrá poner fin a su mandato por el mismo procedimiento"; por su parte, el apartado 3 de ese mismo precepto dispone que "el Presidente del Consejo Europeo no podrá ejercer mandato nacional alguno».
} 
Para cerrar el examen de los perfiles constitucionales del Presidente del Consejo Europeo, resulta pertinente introducir una reflexión sobre su modo de elección, tanto más cuanto que parece perfilarse precisamente - según antes se apuntaba- como el Presidente de la Unión Europea. Pues bien, en mi opinión:

a) Ni se revela adecuado el sistema previsto de nombramiento por el propio Consejo Europeo (artículo I-22.1 del Tratado constitucional), que en definitiva vendrá a reproducir el peso de los intereses estatales y las disputas que ya se han verificado en torno a la designación de los últimos Presidentes de la Comisión (aunque, en el caso del Presidente de ésta, haya de contarse además con la investidura del Parlamento Europeo —artículo l-27.1 del Tratado constitucional-, por lo que desde este punto de vista gozaría de mayor legitimidad democrática el Presidente de la Comisión y bien habría de merecer él la cualidad de Presidente de la Unión).

b) Ni me parece llegado el momento para una elección directa del Presidente del Consejo Europeo como Presidente de la Unión (a través de unas elecciones presidenciales directas como las que se celebran para la elección del Parlamento Europeo), no sólo porque no todos los países de la Unión cuentan con una experiencia presidencialista, sino sobre todo porque incluso con la campaña electoral correspondiente a escala europea resulta hoy por hoy ilusorio elegir a un pretendido "Jefe del Estado Europeo" o de los "Estados Unidos de Europa" con el que todos los ciudadanos de la Unión se sientan identificados o representados, pues falta un demos europeo (apartado IV, infra) ${ }^{36}$ que conduzca a una elección presidencial de tintes europeístas, es decir, más allá de preferencias efectuadas sobre la base de regiones europeas (como podría ser la agrupación del voto en los países nórdicos, en algunos países del Este europeo, etc.).

c) Por todo ello, me decanto como "mal menor" por el momento por una elección indirecta del Presidente del Consejo Europeo, con investidura por parte del Parlamento Europeo, a la manera

36 Sobre la inexistencia actual de ese demos a escala europea, léase ZAGREBELSKY, G.: "Introduzione», en la obra colectiva Diritti e Costituzione nell'Unione Europea, Laterza, Roma-Bari, 2003, pp. V y ss. De manera más amplia, acúdase a RUIPÉREZ, J.: La Constitución europea y la teoría del poder constituyente, Madrid, Biblioteca Nueva, 2000, así como DíEz-PICAZO, L. M.: Constitucionalismo en la Unión Europea, Madrid, Cuadernos Civitas, 2002. 
del sistema parlamentario, en donde el grupo político con mayoría en la Eurocámara habría de ser capaz de proponer un leader al efecto tras las elecciones europeas ${ }^{37}$.

\section{REFLEXIONES FINALES: EL CONSEJO, ¿UN PODER CONSTITUYENTE O UN PODER CONSTITUIDO PARA GENERAR EL DEMOS EUROPEO?}

Antes se ha visto (apartado III.3, supra) que el mencionado artículo IV-443 del Tratado Constitucional confería una especie de cariz "constituyente» o "constitucional» al Consejo Europeo. Esa misma catalogación cabría extenderla al Consejo a la vista de la letra del citado precepto constitucional europeo. A mayor abundamiento, semejante catalogación se intensifica, respecto del Consejo pero, sobre todo, del Consejo Europeo, en el procedimiento de revisión simplificado del Tratado constitucional (artículo IV-444) y en el procedimiento de revisión simplificado relativo a las políticas y acciones internas de la Unión (artículo IV-445). Ciertamente, una vez verificada la eventual entrada en vigor del Tratado constitucional, su reforma posterior propiciará una profundización en la integración europea $y$, como resultado, mayores posibilidades de emergencia de la conciencia europea y de robustecimiento el demos europeo en ciernes.

La Convención presidida por Giscard d'Estaing, constituida el 28 de febrero de 2002, se presentó como la "vertiente orgánica» de la Con-

37 En esta punto, me parecen de gran interés las reflexiones de VíRgALA ForURIA, E.: "El Poder Ejecutivo en la Unión Europea: Consejo y Comisión», Revista de Estudios Políticos, n. ${ }^{\circ}$ 119, 2003, pp. 340-341: "En este marco teórico, no cabe dejar de preguntarse cuál sería la forma de gobierno más adecuada para un eficaz funcionamiento de la Unión europea. El parlamentarismo, presente en la gran mayoría de los Estados de la actual Europa comunitaria, se encuentra con múltiples problemas. (...) La alternativa al parlamentarismo no puede ser la adopción de la forma de gobierno presidencial, pues pienso que no se adapta a la cultura política europea y su funcionamiento práctica deja mucho que desear en el paradigma del presidencialismo, Estados Unidos. El semipresidencialismo, por su parte, tampoco parece que deba acogerse como hipótesis de futuro, ya que su dualidad de poderes efectivos en el Ejecutivo, a pesar de su funcionamiento más o menos eficaz en Francia, puede plantar más problemas que ventajas. Por todo ello, cabría proponer una forma de gobierno para la Unión Europea diferente a las conocidas en los Estados democráticos, y que he denominado semiparlamentaria, centrada en la elección directa del Presidente de la Unión, (...) aunque coincido con quienes señalan que esta opción es adecuada aunque todavía prematura». 
vención presidida por Herzog que dio forma a la potencial "parte dogmática" de la incierta Constitución europea, es decir, la Carta de los derechos fundamentales de la Unión proclamada en el Consejo Europeo de Niza de diciembre de 2000 e integrada como Parte II del Tratado constitucional. Desde luego, sería posible cuestionar los méritos europeístas del uno y del otro. Pero, centrándonos ahora en el primero, ya se comentó que la denominación oficial del Consejo Europeo parece deberse a él, según sus manifestaciones con motivo de la presidencia de turno del segundo semestre de 1974, a la conclusión de la cual se dirigió a la opinión pública en rueda de prensa en estos términos: "iLa Cumbre Europea ha muerto, larga vida al Consejo Europeo!»); y recuérdese, buscando conexiones razonables, que el Consejo Europeo, tanto en el artículo 4 del vigente Tratado de la Unión como en el artículo I-21 del Tratado constitucional, se configura como el actor que ha de dar a la Unión los impulsos necesarios para su desarrollo político-constitucional.

Como también se dijo, la Convención presidida por Giscard d'Estaing comportó una novedad no prevista en los Tratados comunitarios. Tras el "no" del pueblo francés, del pueblo holandés,... al Tratado constitucional de 2004, no sabemos si ya es el tiempo de proclamar asimismo la muerte del modelo "clásico" de conferencia intergubernamental y una larga vida al proceder "convencional» que ha conducido a la elaboración del Tratado constitucional. Sea como fuere, más allá de cuestiones formales ${ }^{38}$, el debate sustancial en torno a una "constitución material" para Europa (ya que formalmente es un tratado internacional - $\mathrm{O}$, a lo sumo, un producto híbrido que contienen elementos convencionales y constitucionales - ${ }^{39}$ ) ha sido positivo ${ }^{40}$ : de manera emblemática, podría afirmarse con tal filosofía que la Carta de los derechos fundamentales desplegaría un "efecto sustancialmente constitucional", al constituir un impulso para que los ciudadanos europeos se identifiquen con los valores comunes enunciados en el artículo 6.1 el Tratado de la Unión Europea y favorecerse de tal suerte el control social de las posibles violaciones de los mismos, "lo que acaba finalmente

38 Giscard d'Estaing mostró su satisfacción por el hecho de que el proyecto de Tratado constitucional quedara aprobado en el Consejo Europeo de Bruselas del mes de junio de 2004 manteniéndose el noventa y cinco por ciento del documento proyectado: véase GISCARD D'ESTAING, V.: "Vite, la Constitution de l'Europe!», Le Monde, mardi 10 juillet 2004, p. 1).

${ }^{39}$ Así lo expresa G. AMATo en la entrevista que aparece bajo el título "Amato: è un ibrido, ma dico sì alla Costituzione», en el diario L'Unità, 28 ottobre 2004, p. 7.

${ }^{40}$ Acúdase a la ya clásica obra de MORTATI, C.: La costituzione in senso materiale, Giuffrè, Milano, 1940. 
por conllevar también -y esa es la cuestión- un efecto "conformador" acerca del modo de ser de las estructuras organizativas de los Estados ${ }^{41}$.

Así pues, en el contexto de este debate material, precisamente la Carta de los derechos fundamentales, junto con los principios básicos establecidos en la Parte I, constituye el núcleo sustancial del Tratado constitucional. Si éste no es capaz de superar el proceso de ratificaciones en el seno de los veinticinco Estados miembros de la Unión y, en consecuencia, no media un consenso respecto a su necesidad política (una unión política europea, una especie de Estados Unidos de Europa), o sobre su necesidad técnica (un documento único en donde se consoliden y simplifiquen los tratados comunitarios -es obvio que la denominación formal como "Constitución" resulta compleja si no tiene el soporte político de un inexistente poder constituyente europeo-), la Carta de los derechos fundamentales tal vez se convierta en el elemento material que permita salvar y justificar en parte el trabajo emprendido por las Convenciones presididas por Herzog y por Giscard d'Estaing. En este panorama, al margen del alcance de los procedimientos de revisión establecidos en el propio Tratado constitucional (cuya operatividad pasa, lógicamente, por la entrada en vigor de éste), la solución seguramente más sencilla para recuperar parte del Tratado constitucional sea la recuperación de la Carta de los derechos fundamentales como un Protocolo anejo a los Tratados comunitarios, es decir, conseguir lo que no fuimos capaces de acordar en el Consejo Europeo de Niza de diciembre de 2000. Por otra parte, sería posible plantear asimismo que, mediante una decisión del Consejo (en esa función de poder constituido para generar el demos europeo), se retomaran algunas cuestiones orgánicas previstas en el Tratado constitucional (por ejemplo, en lo relativo a los miembros de la Comisión). Otra alternativa, en última instancia, consistiría, si no se renegocia el texto constitucional europeo, en plantear la aplicación de la Constitución en aquellos países que la hayan ratificado a modo de "cooperaciones reforzadas", lo que obviamente presenta el inconveniente de la consabida "Europa de las velocidades" y la consiguiente difícil consecución de un "sentimiento constitucional europeo".

En el marco de esas posibilidades, en lo que atañe al Consejo, es cierto que tanto el vigente Derecho de la Unión como el Tratado cons-

41 PACE, A.: "¿Para qué sirve la Carta de los Derechos Fundamentales de la Unión Europea? Notas preliminares», Teoría y Realidad Constitucional, n. ${ }^{\circ}$ 7, 2001, p. 182. 
titucional siguen confiriendo un peso importante a los intereses estatales representados en su seno, pero contrapesando esos intereses con el interés supranacional; y ello viene avalado por la jurisprudencia reciente sobre la denominada "cláusula de flexibilidad" (artículo 308 del Tratado de la Comunidad Europea -anterior artículo 235- y artículo I-18 del Tratado constitucional) en cuestiones sensibles: así, la Sentencia del Tribunal de Primera Instancia de 21 de septiembre de 2005 (asunto T-306/01), dictada en el caso Ahmed Ali Yusuf y Al Barakaat International Foundation contra Consejo y Comisión, versó sobre medidas restrictivas (congelación de fondos) adoptadas en el marco de la Política exterior y de seguridad común contra personas y entidades asociadas a Bin Laden, la Red Al-Qaida y los talibanes. Es interesante resaltar que el fallo fue desestimatorio, dando con ello respaldo a la consolidación del segundo pilar con apoyo en la cláusula de flexibilidad del actual artículo 308 TCE y preceptos concordantes ${ }^{42}$. Es cierto que esa cláusula ha venido consolidando una práctica por medio de la cual el Consejo ha ido incrementando sus poderes por lo que, desde cierto punto de vista, podría pensarse en el ensanchamiento de las competencias de la Unión en detrimento de los Estados miembros; sin embargo, recuérdese que se exige la unanimidad en el Consejo, de manera que, además de las cautelas interpretativas establecidas en la jurisprudencia comunitaria respecto a esa potencial expansión de competencias, realmente se está apostando al tiempo por una defensa de los intereses estatales. De la sentencia se desprende, además, que la Unión y los Estados miembros, en el seno del Consejo (y de la Comisión) han cerrado filas ante una cuestión tan trascendental como es el terrorismo internacional.

Retomando la cuestión del sentimiento constitucional, se impone señalar que incluso en ausencia de una verdadera Constitución europea, no ha de atender solamente al interés prevalentemente económico de la Unión, ni por tanto a la "identidad monetaria» basada en el euro (que figura entre los símbolos de la Unión en el artículo l-8 del Tra-

42 En el mismo sentido, la sentencia del Tribunal de Primera Instancia de idéntica fecha, dictada en el caso Yassin Abdullah Kadi contra Consejo y Comisión (asunto T-315/01). Un interesante análisis sobre el alcance de la cláusula de flexibilidad existente en la Unión Europea en clave de legitimidad democrática, con énfasis en los resortes de control que la acompañan y en comparación con la interpretación efectuada de esa misma cláusula en Estados Unidos de América por su Tribunal Supremo, en el trabajo de Astola MADARIAGA, J.: «De la legitimidad democrática de la Unión Europea y de la legitimación democrática de sus decisiones: una reflexión sobre el proyecto de Constitución Europea», Teoría y Realidad Constitucional, n. ${ }^{\circ}$ 15, 2004, en especial, pp. 222-226. 
tado constitucional), sino también a otros elementos que generen un "espíritu europeo": una cultura europea de respeto de los derechos fundamentales (no únicamente de las libertades económicas y de los derechos cívico-políticos, sino también de los derechos sociales, de solidaridad, de tolerancia, etc.) ${ }^{43}$, de otros símbolos europeos (himno europeo, etc. —recogidos asimismo en el mencionado artículo l-8- $)^{44}$ y de las propias instituciones europeas ${ }^{45}$. De la misma manera que los ciudadanos europeos ostentamos los derechos de sufragio activo y pasivo (en elecciones municipales y europeas), habría que tender decididamente hacia la implantación de una especie de sufragio universal en clave socioeconómica, con un mínimo social garantizado o una renta mínima de ciudadanía (lucha contra la exclusión social) ${ }^{46}$. Con estos parámetros, al lado de la vertiente económica, se habría de enfatizar la faceta social y socializante de la ciudadanía, haciéndose hincapié asimismo en la necesidad de una educación en cultura europea - federalismo, historia europea $y$, sobre todo, en derechos fundamentales a escala europea y mundial- ${ }^{47}$. $\mathrm{Y}$ una reflexión ulterior: los derechos reconocidos a los ciudadanos en el Tratado constitucional de 2004 todavía no impiden ciertas asimetrías, como por ejemplo la información y la participación de unos ciudadanos, y de otros no, en las cuestiones

43 Una crítica en torno al desequilibrio entre las libertades económicas y los derechos sociales en el trabajo de Alegre MARTínEZ, M. A.: «Los derechos sociales en la Carta de los derechos fundamentales de la Unión Europea», en el colectivo Escritos sobre Derecho europeo de los derechos sociales (coord. por L. Jimena Quesada), Valencia, Tirant lo Blanch, 2004.

${ }_{44}$ Puede leerse Alegre Martínez, M. A.: «El himno europeo: notas musicales en clave constitucional", Cuadernos Constitucionales de la Cátedra Fadrique Furió Ceriol, n. ${ }^{\circ} 32,2000$.

45 Sobre el deficitario conocimiento de las instituciones europeas, y especialmente del Consejo, es interesante constatar los resultados al Cuestionario sobre democratización e instituciones realizado por el Movimiento europeo (Consejo federal español), de acceso en: http://www.movimientoeuropeo.org/ampliar_convencion. asp?id=20. Así, por ejemplo, de las dos primeras cuestiones se desprende que el Consejo es, de las tres instituciones políticas (junto al Parlamento Europeo y a la Comisión), la menos conocida y la que curiosamente se piensa que ostenta menos poder decisorio.

46 Morley-Fletcher, E.: «Reddito di cittadinanza e democrazia economica. Certezze per rischiare», Nuova Rassegna Sindacale, n. ${ }^{\circ} 23,1989$, p. 3.

47 Léase CHITI-BATELLI, A.: Éducation fédéraliste et culture européenne, Nice, Presses d'Europe, 1992; así como PÉREZ VERA, E.: "Los ciudadanos europeos y la enseñanza de las materias comunitarias", en el colectivo Cuestiones actuales del Derecho Comunitario Europeo (dir. J. M. Peláez Marón), vol. III, Universidad de Córdoba, 1995. 
europeas fundamentales («constitucionales»)48; así, de la misma manera que se ha reconocido positivamente en el Tratado constitucional la iniciativa legislativa ciudadana (artículo l-47.4), hay que lamentar como circunstancia negativa que no se haya establecido un referéndum europeo para estas cuestiones "constitucionales" europeas ${ }^{49}$, lo que en España se puso de manifiesto con motivo del referéndum de 20 de febrero de $2005^{50}$.

48 Véase Alegre Martínez, M. A., y Jimena Quesada, L.: "La Carta de los derechos fundamentales de la Unión Europea tras su integración en el Tratado constitucional: asimetrías, inconsistencias y paradojas", Colóquio Ibérico: Constituçao Europeia. Homenagem ao Doutor Francisco Lucas Pires. Boletim da Faculdade de Direito, Studia luridica 84, Universidad de Coimbra, 2005.

${ }^{49}$ Con tal enfoque, Auer, A., y FlaUSS, J. F. (coords.): Le référendum européen, Bruxelles, Bruylant, 1997, así como JIMENA QUESADA, L.: "Los ciudadanos como actores en el proceso de construcción europea. Hacia una Teoría del Estado Europeo", Cuadernos Europeos de Deusto, n. ${ }^{\circ} 24,2001$, y "Los instrumentos de democracia directa y la nueva Constitución Europea», en la obra colectiva de tres tomos Comentarios a la Constitución Europea, ya cit.

50 JIMENA QUESADA, L.: "El derecho de participación política en el referéndum sobre la Constitución europea", Levante-El Mercantil valenciano (edición de Castellón, del miércoles, 16 de febrero de 2005, p. 4. 